\title{
Polymorphisms of cell cycle regulator genes $C$ CND1 G870A and TP53 C215G: Association with colorectal cancer susceptibility risk in a Malaysian population
}

\author{
MOHD NIZAM ZAHARY ${ }^{1,2}$, ABDUL AZIZ AHMAD AIZAT ${ }^{1}$, \\ GURJEET KAUR $^{3}$, LEE YEONG YEH ${ }^{4}$, MAYA MAZUWIN ${ }^{5}$ and RAVINDRAN ANKATHIL ${ }^{1}$
}

\begin{abstract}
${ }^{1}$ Human Genome Centre, School of Medical Sciences, University of Science Malaysia Health Campus, Kubang Kerian, Kelantan 16150; ${ }^{2}$ School of Diagnostic and Biomedicine, Faculty of Health Sciences, Sultan Zainal Abidin University, Kuala Terengganu, Terengganu 21300; ${ }^{3}$ Institute for Research in Molecular Medicine, University of Science Malaysia, Minden, Penang 11800; Departments of ${ }^{4}$ Medicine and ${ }^{5}$ Surgery, School of Medical Sciences, University of Science Malaysia Health Campus, Kubang Kerian, Kelantan 16150, Malaysia
\end{abstract}

Received October 8, 2014; Accepted July 7, 2015

DOI: $10.3892 / \mathrm{ol} .2015 .3728$

\begin{abstract}
Colorectal cancer (CRC) occurs as a more common sporadic form and a less common familial form. Our earlier analysis of germline mutations of mismatch repair genes confirmed only $32 \%$ of familial CRC cases as Lynch syndrome cases. It was hypothesized that the remaining familial aggregation may be 'polygenic' due to single nucleotide polymorphisms (SNPs) of low penetrance genes involved in cancer predisposition pathways, such as cell cycle regulation and apoptosis pathways. The current case-control study involving 104 CRC patients (52 sporadic and 52 familial) and 104 normal healthy controls investigated the contribution of the SNPs cyclin D1 (CCNDI) G870A and tumor protein p53 (TP53) C215G in modulating familial and sporadic CRC susceptibility risk. DNA was extracted from peripheral blood and the polymorphisms were genotyped by employing a polymerase chain reaction-restriction fragment length polymorphism method. The association between these polymorphisms and CRC susceptibility risk was calculated using a binary logistic regression analysis and deriving odds ratios (ORs). The A/A variant genotype of $C C N D I$ and $\mathrm{G} / \mathrm{G}$ variant genotype of TP53 exhibited a significantly greater association with the risk of sporadic CRC [CCNDI: OR, 3.471; 95\% confidence interval (CI), 1.443-8.350; $\mathrm{P}=0.005$. TP53: OR, 2.829; CI, 1.119-7.152; $\mathrm{P}=0.026]$ as well as familial CRC susceptibility (CCNDI: OR, 3.086; CI, 1.270-7.497;
\end{abstract}

Correspondence to: Professor Ravindran Ankathil, Human Genome Centre, School of Medical Sciences, University of Science Malaysia Health Campus, Jalan Raja Perempuan Zainab I, Kubang Kerian, Kelantan 16150, Malaysia

E-mail: rankathil@hotmail.com

Key words: colorectal cancer, familial, sporadic, CCND1 G870A, TP53 C215G
$\mathrm{P}=0.019$. TP53: OR, 3.048; CI, 1.147-8.097; $\mathrm{P}=0.030$ ). The results suggest a potential role of the SNPs CCND1 G870A and TP53 C215G in the modulation of sporadic and familial CRC susceptibility risk.

\section{Introduction}

Colorectal cancer (CRC) is the third most common type of cancer among males and the second most common type among females worldwide, accounting for 746,000 and 614,000 cases in 2012, respectively (1). The incidence of CRC is rapidly increasing in developing countries, including Malaysia, where it ranks as the second most common cancer in men and women, with a total of 2,246 cases diagnosed in $2007(2,3)$. CRC occurs as a more frequent sporadic form and a less frequent familial form. Familial aggregation of CRC cases results from the inheritance of germline mutations of mismatch repair (MMR) genes. Previously, from a cohort of CRC patients, we identified 68 suspected Lynch syndrome cases. However, an analysis of germline mutations of the MMR genes, MLH1, MSH2, MSH6 and PMS2, confirmed only $32 \%$ of these CRC cases as Lynch syndrome cases (4). This indicated the existence of additional genetic susceptibility factors that account for familial risk and which remain to be elucidated. It was hypothesized that MMR-non-mutated familial aggregation may be largely 'polygenic' due to single nucleotide polymorphisms (SNPs) of low penetrance genes involved in cancer predisposition pathways, including cell cycle regulation and apoptosis.

Cyclin D1 protein, encoded by $C C N D 1$, is a key regulator of the cell cycle which modulates the transition from G1 to S phase via cyclin-dependent kinases (CDKs) during cell division (5). However, the overexpression of cyclin D1 due to genetic variation may disrupt cell cycle control and potentially induce the development of cancers (6). A common polymorphism of $C C N D 1, \mathrm{G} 870 \mathrm{~A}$, has been widely investigated in numerous case-control studies for its association with different types of cancer, including sporadic CRC, 
familial CRC, squamous cell carcinoma of the head and neck, urinary tract bladder cancer and prostate cancer, in various populations (7-10).

Tumor protein p53, encoded by the TP53 gene, plays a major role in regulating cell cycle progression, DNA repair, cellular growth and apoptosis $(11,12)$. As an important tumor suppressor gene, the encoded protein acts to suppress tumorigenesis and control the cell cycle checkpoint and apoptosis under physiological stress. A common variation in TP53, the $\mathrm{C}$ to $\mathrm{G}$ substitution at codon 72 , has been demonstrated to alter the normal function of p53. The change of amino acid from arginine to proline in a proline-rich region of the protein may affect the role of p53 in apoptosis (13). To date, a small number of case-control studies have been conducted to investigate the potential association of the CCND1 G870A and TP53 C215G polymorphisms with CRC susceptibility risk in various populations $(14,15)$. However, no reports are available from Malaysian populations. Therefore, these two SNPs were selected as candidates for investigation, and the current case-control study was undertaken to investigate the genotype frequencies of CCND1 G870A and TP53 C215G polymorphisms and determine their role in modulating familial and sporadic CRC susceptibility risk in Malaysian subjects.

\section{Materials and methods}

Study subjects. Research conducted at the Malaysian Ministry of Health hospitals in the present study was approved by the Research and Ethics Committee of the School of Medical Sciences, University of Science Malaysia (USM; Kubang Kerian, Malaysia) and the National Institutes of Health (registration ID: NMRR-08-711-1866). Subjects were recruited from various hospitals in Malaysia, including Hospital USM, Hospital Sultanah Bahiyah (Alor Setar, Malaysia), Hospital Raja Perempuan Zainab II (Kota Bharu, Malaysia) and Hospital Queen Elizabeth (Kota Kinabalu, Malaysia) between March 1, 2008 and February 28, 2011. This case-control study involved 208 study subjects, comprising 52 histopathologically confirmed sporadic CRC patients, 52 familial CRC patients and 104 healthy normal controls. Initially, 68 families with suspected Lynch syndrome [also known as hereditary nonpolyposis colorectal cancer (HNPCC)] were identified based on Bethesda Guidelines (16): i) CRC and age <50 years; ii) presence of synchronous or metachronous colorectal or other HNPCC-associated tumors, regardless of age; iii) CRC with microsatellite instability-positive morphology and age $<60$ years; iv) CRC and one or more first-degree relatives with CRC or other HNPCC-related tumors, with one of the cancers occurring $<50$ years of age; or v) CRC and two or more firstor second-degree relatives with CRC or other HNPCC-related tumor (regardless of age), including endometrial, stomach, ovarian, cervical, esophageal, leukemia, thyroid, bladder, ureter and renal pelvis, biliary tract, small bowel, breast, pancreas, liver, larynx, bronchus, lung and brain cancers (glioblastoma), sebaceous gland adenomas and keratoacanthomas. Personal and demographic details of the patients, including family history of CRC, were collected and recorded. CRC patients with a strong family history of CRC among first- or second-degree relatives were subjected to a detailed pedigree analysis. Pedigrees of the 68 suspected Lynch syndrome families were prepared, and these patients were subjected to protein expression and germline mutation analysis of MMR genes. Of these, 16 cases in which germline mutations of any of the 4 MMR genes, MLH1, MSH2, MSH6 or PMS2, were identified were excluded from the present study, and the remaining 52 cases were included as familial CRC cases. Cases with known familial adenomatous polyposis, ulcerative colitis or Crohn's disease, or any other previous malignancy as stated in the pathology reports were also excluded. For comparison, 52 histopathologically confirmed sporadic colorectal cancer patients and 104 normal controls were also included in the present study. Controls were normal healthy individuals who visited Hospital USM for problems unrelated to cancer and were aged 30-65 years. The control subjects were biologically unrelated to the patients and were cancer-free. Epidemiological data was collected from patients using a pre-structured questionnaire comprising questions on socio-demographic status, physical status, dietary factors, occupation, tobacco/alcohol habits, previous illness and radiation exposure.

Genotyping of CCND1 G870A and TP53 C215G polymorphisms. Blood samples $(3 \mathrm{ml})$ were collected from study participants after obtaining informed consent. Genomic DNA was extracted from blood samples using a QIAamp DNA Blood Mini kit (Qiagen, Hilden, Germany). Genotyping of CCND1 G870A and TP53 C215G polymorphisms was conducted using polymerase chain reaction (PCR)-restriction fragment length polymorphism. Regions in CCNDI and TP53 containing the polymorphic site were amplified using the following primers: CCND1 G870A forward, 5'-GTTATGTTTGAGTCAACAGTGG-3', and reverse, 5'-TCTAGGAGCAGTGGAAGAAG-3' (product length,574 bp); and TP53 forward, 5'-TCAAACATCCTGTCCCTACT-3', and reverse, 5'-CTGCGATTAAAGGCTGTGGA-3' (product length, $458 \mathrm{bp}$ ). PCR was performed in a final volume of $25 \mu \mathrm{l}$, consisting of $2 \mathrm{mM} \mathrm{MgCl}$, $1 \mathrm{X}$ GeneAmp PCR Buffer II, $0.2 \mathrm{mM}$ dNTPs, $0.4 \mu \mathrm{M}$ of each forward and reverse specific primers, $4 \mathrm{ng} / \mu \mathrm{l}$ of template DNA and $1 \mathrm{U}$ of AmpliTaq Gold DNA Polymerase (reagents purchased from Applied Biosystems Life Technologies, Foster City, CA, USA). PCR was conducted in an Eppendorf Mastercycler Gradient (Eppendorf, Hamburg, Germany) and the conditions were as follows: Pre-denaturation at $94^{\circ} \mathrm{C}$ for $5 \mathrm{~min} ; 35$ cycles of denaturation at $94^{\circ} \mathrm{C}$ for $30 \mathrm{sec}$, annealing at $57^{\circ} \mathrm{C}(C C N D 1 \mathrm{G} 870 \mathrm{~A})$ or $56^{\circ} \mathrm{C}(T P 53 \mathrm{C} 215 \mathrm{G})$ for $30 \mathrm{sec}$, and extension at $72^{\circ} \mathrm{C}$ for $30 \mathrm{sec}$; and a $72^{\circ} \mathrm{C}$ final extension step for $5 \mathrm{~min}$. Amplicons were then detected by gel electrophoresis on a $2 \%$ agarose gel. Following amplification, PCR products containing the CCND1 G870A or TP53 C215G polymorphic sites were digested using $B s r \mathrm{I}$ and $B s t \mathrm{UI}$ restriction enzymes (New England Biolabs Inc., Ipswich, MA, USA) at $65^{\circ} \mathrm{C}$ for $1 \mathrm{~h}$ or $60^{\circ} \mathrm{C}$ for $1 \mathrm{~h}$, respectively. For CCND1 G870A, the $\mathrm{G}$ allele was not cleaved by $B s r I$ and thus yielded a single fragment (574 bp), whereas the A allele was cleaved and therefore produced two fragments (388 and $186 \mathrm{bp}$ ); the heterozygous genotype yielded three fragments (574, 388 and $186 \mathrm{bp})$. Genotypes were categorized as homozygous wild type $(\mathrm{G} / \mathrm{G})$, heterozygous $(\mathrm{G} / \mathrm{A})$ or homozygous variant $(\mathrm{A} / \mathrm{A})$ based on the fragment sizes, as shown in Fig. 1. For the TP53 C215G polymorphism, the $\mathrm{C}$ allele was cleaved by $B s t \mathrm{UI}$ and thus yielded two fragments (321 and $137 \mathrm{bp}$ ) whereas the $\mathrm{G}$ 
allele was not cleaved and produced a single fragment (458 bp), and the heterozygous genotype yielded three fragments (458, 321 and $137 \mathrm{bp})$. The genotype was categorized as homozygous wild type $(\mathrm{C} / \mathrm{C})$, heterozygous $(\mathrm{C} / \mathrm{G})$ and homozygous variant (G/G) based on the fragment sizes (Fig. 2).

Statistical analysis. The $\chi^{2}$ test was used to compare the frequency distribution of CCND1 G870A and TP53 C215G genotypes in sporadic CRC patients, familial CRC patients and controls. The odds ratios (ORs) and $95 \%$ confidence intervals (CIs) were calculated using a binary logistic regression method (SPSS software version 18; SPSS, Inc., Chicago, IL, USA) to assess the risk association between CCND1 G870A and TP53 C215G polymorphisms and sporadic CRC and familial CRC. All statistical tests were two sided and $\mathrm{P}<0.05$ was considered to indicate statistical significance.

\section{Results}

A total of 104 CRC patients (52 sporadic CRC and 52 familial CRC patients) and 104 normal controls were recruited. Of the 52 sporadic CRC patients, 28 were male and 24 were female, with a mean age ( \pm standard deviation) of $60.31 \pm 11.29$ years. The 52 familial CRC patients comprised 30 males and 22 females, with a mean age of $45.62 \pm 10.60$ years. The normal controls comprised of 50 males and 54 females with a mean age of $49.62 \pm 10.78$ years (Table I). The frequency distribution of SNP genotypes was evaluated after genotyping the 208 study subjects. The genotype frequencies of CCND1 G870A and TP53 C215G polymorphisms in CRC patients (sporadic CRC and familial CRC cases together and separately) and normal controls are shown in Table II.

The association of CCND1 G870A and TP53 C215G polymorphisms with CRC susceptibility risk was analyzed using a binary logistic regression analysis. ORs were calculated relative to subjects, with the wild type $\mathrm{G} / \mathrm{G}$ genotype of $C C N D 1$ and the C/C genotype of TP53 used as references. The A/A variant genotype of CCND1 (OR, 3.471; CI, 1.443-8.350; $\mathrm{P}=0.005)$ and $\mathrm{G} / \mathrm{G}$ variant genotype of TP53 (OR, 2.829; CI, 1.119-7.152; $\mathrm{P}=0.026$ ) were revealed to be significantly associated with the risk of sporadic CRC (Table III). Notably, these variant genotypes of CCNDI (A/A) and TP53 (G/G) also exhibited a significantly greater association with the risk of familial CRC relative to the wild type genotypes (CCNDI: OR, 3.086; CI, 1.270-7.497; $\mathrm{P}=0.019$. TP53: OR, 3.048; CI, 1.147-8.097; $\mathrm{P}=0.030)($ Table IV).

\section{Discussion}

The incidence of CRC has been increasing rapidly, and the disease has become one of the leading causes of cancer-related mortality worldwide in recent years. As a result, large numbers of research studies have been directed towards the investigation of CRC, particularly with regard to its etiology, prevention and treatment (17-19).

Colorectal carcinogenesis is a complex, gradual and multistep process involving various factors $(20,21)$. The protein encoded by $C C N D 1$, cyclin D1, is involved in colorectal carcinogenesis in its role as one of the key regulatory proteins of the cell cycle transition from G1 to S phase (5,22). CCND1 G870A (Pro241Pro)
Table I. Distribution of gender and age among colorectal cancer cases and controls.

\begin{tabular}{lccc}
\hline & \multicolumn{2}{c}{ Colorectal cancer } & \\
\cline { 2 - 3 } Variable & $\begin{array}{c}\text { Sporadic } \\
(\mathrm{n}=52)\end{array}$ & $\begin{array}{c}\text { Familial } \\
(\mathrm{n}=52)\end{array}$ & $\begin{array}{c}\text { Control } \\
(\mathrm{n}=104)\end{array}$ \\
\hline Gender, $\mathrm{n}$ & & & \\
Male & 28 & 30 & 50 \\
Female & 24 & 22 & 54 \\
Age, years & & & \\
Range & $36-83$ & $26-72$ & $27-72$ \\
Mean \pm SD & $60.31 \pm 11.29$ & $45.62 \pm 10.60$ & $49.62 \pm 10.78$ \\
\hline
\end{tabular}

$\mathrm{SD}$, standard deviation.

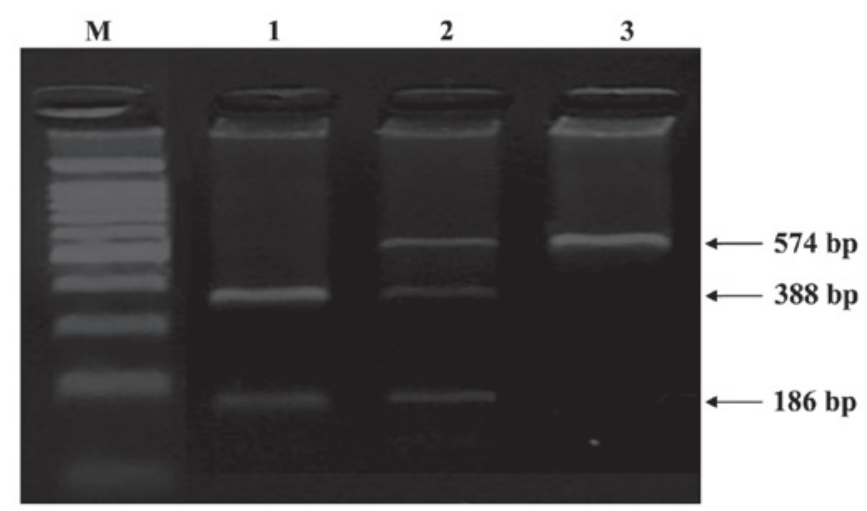

Figure 1. Representative gel electrophoresis of polymerase chain reaction-restriction fragment length polymorphism analysis of CCND1 G870A. Lanes: M, 100 bp marker; 1, homozygous variant genotype (388 and $186 \mathrm{bp}$ ); 2 , heterozygous genotype $(574,388$ and $186 \mathrm{bp}) ; 3$, homozygous wild type genotype (574 bp).

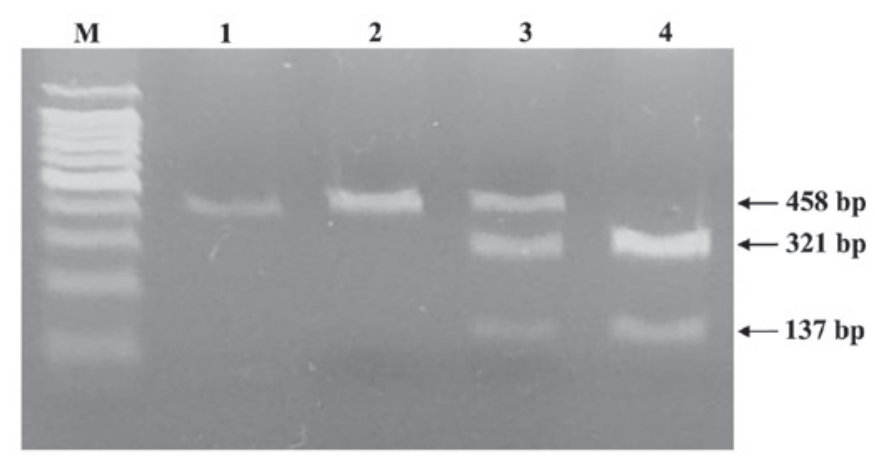

Figure 2. Representative gel electrophoresis of polymerase chain reaction-restriction fragment length polymorphism analysis of TP53 C215G. Lanes: M, 100 bp marker; 1 and 2, homozygous variant genotype (458 bp); 3 , heterozygous genotype $(458,321$ and $137 \mathrm{bp})$; 4, homozygous wild type genotype (321 and $137 \mathrm{bp}$ ).

is a silent variant in which the alteration of amino acids does not occur. However, as this variation is in the last nucleotide of exon 4, it may lead to the alternative splicing of CCND1 mRNA. Both alleles are capable of producing two different transcripts, a normal splicing exon 4 and exon 5, known as 'transcript a', 
Table II. Genotype frequencies of CCND1 G870A and TP53 C215G polymorphisms in colorectal cancer cases and normal controls.

\begin{tabular}{|c|c|c|c|c|c|c|c|}
\hline \multirow[b]{2}{*}{ Polymorphism } & \multirow[b]{2}{*}{ Controls, n (\%) } & \multicolumn{2}{|c|}{ Total cases } & \multicolumn{2}{|c|}{ Sporadic CRC } & \multicolumn{2}{|c|}{ Familial CRC } \\
\hline & & $\mathrm{n}(\%)$ & P-value & $\mathrm{n}(\%)$ & P-value & $\mathrm{n}(\%)$ & P-value \\
\hline \multicolumn{8}{|l|}{ CCND1 G870A } \\
\hline $\mathrm{G} / \mathrm{G}$ & $36(34.6 \%)$ & $20(19.2 \%)$ & $0.017^{\mathrm{a}}$ & $10(19.2 \%)$ & $0.047^{\mathrm{a}}$ & $10(19.2 \%)$ & $0.047^{\mathrm{a}}$ \\
\hline $\mathrm{G} / \mathrm{A}$ & $40(38.5 \%)$ & $33(31.7 \%)$ & 0.309 & $15(28.8 \%)$ & 0.236 & $18(34.6 \%)$ & 0.640 \\
\hline $\mathrm{A} / \mathrm{A}$ & $28(26.9 \%)$ & $51(49.1 \%)$ & $0.001^{\mathrm{a}}$ & $27(52.0 \%)$ & $0.002^{\mathrm{a}}$ & $24(46.2 \%)$ & $0.016^{\mathrm{a}}$ \\
\hline \multicolumn{8}{|l|}{ TP53 C215G } \\
\hline $\mathrm{C} / \mathrm{C}$ & $33(31.7 \%)$ & $27(26.0 \%)$ & 0.358 & $15(28.9 \%)$ & 0.713 & $12(23.1 \%)$ & 0.261 \\
\hline $\mathrm{C} / \mathrm{G}$ & $57(54.8 \%)$ & $43(41.3 \%)$ & 0.052 & $19(36.5 \%)$ & $0.031^{\mathrm{a}}$ & $24(46.2 \%)$ & 0.308 \\
\hline $\mathrm{G} / \mathrm{G}$ & $14(13.5 \%)$ & $34(32.7 \%)$ & $0.001^{\mathrm{a}}$ & $18(34.6 \%)$ & $0.002^{\mathrm{a}}$ & $16(30.7 \%)$ & $0.010^{\mathrm{a}}$ \\
\hline Total & $104(100 \%)$ & $104(100 \%)$ & & $52(100 \%)$ & & $52(100 \%)$ & \\
\hline
\end{tabular}

${ }^{\text {ap }}<0.05$ vs. controls, statistically significant.

Table III. Association of CCND1 G870A and TP53 C215G polymorphisms with sporadic CRC susceptibility risk.

\begin{tabular}{lccc}
\hline Polymorphism & Sporadic CRC, $n$ & Controls, $n$ & OR $(95 \%$ CI $)$ \\
\hline CCND1 G870A & & & \\
G/G & 10 & 36 & $1.000(\text { Ref. })^{\mathrm{a}}$ \\
G/A & 15 & 40 & $1.350(0.539-3.381)$ \\
A/A & 27 & 28 & $3.471(1.443-8.350)$ \\
TP53 C215G & & & \\
C/C & 15 & 33 & $1.000(\text { Ref. })^{\mathrm{a}}$ \\
C/G & 19 & 57 & $0.733(0.329-1.634)$ \\
G/G & 18 & 14 & $2.829(1.119-7.152)$ \\
Total & 52 & 104 & $0.005^{\mathrm{b}}$ \\
\hline
\end{tabular}

a'Genotype served as reference category; ${ }^{\mathrm{P}}<0.05$, statistically significant. CRC, colorectal cancer; OR, odds ratio; CI, confidence interval.

Table IV. Association of CCND1 G870A and TP53 C215G polymorphisms with familial CRC susceptibility risk.

\begin{tabular}{|c|c|c|c|c|}
\hline Polymorphism & Familial CRC, n & Controls, $\mathrm{n}$ & OR $(95 \%$ CI) & P-value \\
\hline \multicolumn{5}{|l|}{ CCND1 G870A } \\
\hline $\mathrm{G} / \mathrm{G}$ & 10 & 36 & 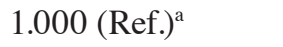 & - \\
\hline G/A & 18 & 40 & $1.620(0.662-3.963)$ & 0.374 \\
\hline $\mathrm{A} / \mathrm{A}$ & 24 & 28 & $3.086(1.270-7.497)$ & $0.019^{\mathrm{b}}$ \\
\hline \multicolumn{5}{|l|}{ TP53 C215G } \\
\hline $\mathrm{C} / \mathrm{C}$ & 12 & 33 & 1.000 (Ref. $^{\mathrm{a}}$ & - \\
\hline $\mathrm{C} / \mathrm{G}$ & 24 & 57 & $1.103(0.488-2.496)$ & 0.806 \\
\hline $\mathrm{G} / \mathrm{G}$ & 16 & 14 & $3.048(1.147-8.097)$ & $0.030^{\mathrm{b}}$ \\
\hline Total & 52 & 104 & & \\
\hline
\end{tabular}

${ }^{\mathrm{a}}$ Genotype served as reference category; ${ }^{\mathrm{P}}<0.05$, statistically significant. CRC, colorectal cancer; OR, odds ratio; CI, confidence interval.

and an alternative transcript, 'transcript b', lacking exon 5 , the exon comprising a PEST domain responsible for the degradation of cyclin D1 protein $(23,24)$. Therefore, it has been reported that the variant A allele may produce a cyclin D1 protein with an increased half life, and the resulting accumulation of the protein may promote cell proliferation (25). 
According to Fearon and Vogelstein (26), colorectal carcinogenesis involves a number of genetic changes that include mutation of certain critical genes, such as TP53, and these mutations accumulate during the progression from normal epithelium to carcinoma. TP53 is one of the most extensively studied genes due to its crucial role in regulating the cell cycle, apoptosis, inhibition of angiogenesis and cellular senescence (27). Mutations or variations in TP53 may completely diminish the function of the p53 protein, and thus may promote cell proliferation and carcinogenesis. The amino acid substitution caused by the C215G SNP may alter the conformation of the protein and, therefore, its ability to bind to elements in target genes, and may affect the stability and interaction of the protein with the other proteins $(28,29)$. Previous studies have described functional differences that are caused by these two alleles in TP53. For example, Pim and Banks (30) reported that the wild type $\mathrm{G}$ (Arg72) allele is more efficient in promoting apoptosis compared with the variant $\mathrm{C}$ (Pro72) allele. A similar finding also has been observed by Marin et al (31), who reported that the mutant $\mathrm{p} 53$ protein exhibited a reduced efficacy during apoptosis compared with the Arg allele protein. Thus, these studies provide evidence that variation in TP53 may lead to abnormal protein function and contribute to cell proliferation and cancer.

The present study investigated the genotype frequencies of CCND1 G870A and TP53 C215G polymorphisms and the potential association with susceptibility risk in Malaysian CRC patients. The results revealed that the variant genotypes of CCND1 (A/A) and TP53 (G/G) have a significantly higher risk association with sporadic $\mathrm{CRC}$ relative to the homozygous wild type genotypes (OR, 3.471 and 2.829, respectively; $\mathrm{P}<0.05$; Table III). In addition, the variant genotypes of the two SNPs exhibited a significantly higher risk association with familial CRC compared with the wild type genotypes (OR, 3.086 and 3.048, respectively; $\mathrm{P}<0.05$; Table IV). The results suggest that individuals with the A/A genotype of CCND1 G870A and G/G genotype of TP53 C215G have a three-fold higher risk for CRC development compared with individuals possessing the $\mathrm{G} / \mathrm{G}$ and $\mathrm{C} / \mathrm{C}$ wild type genotypes.

The association of the CCND1 G870A polymorphism with CRC susceptibility risk has been reported previously in a number of studies (32-34). The present results are in concordance with studies conducted by Hong et al (14) and Jiang et al (35), in which the A/A genotype of CCNDI G870A was found to be associated with CRC susceptibility risk in Singaporean and Indian patients (OR, 2.4 and 1.56, respectively). Another Indian case-control study conducted in a population of Kashmiri ethnicity also identified an association between the variant genotype of CCND1 G870A and risk of CRC, with a two-fold increase in OR relative to the wild type genotype (34). Previous meta-analyses involving numerous case-control studies also demonstrated an association between CCNDI G870A polymorphism and CRC susceptibility risk $(32,33)$, suggesting that the CCND1 870A allele may be a low-penetrant risk factor for CRC.

On the other hand, conflicting results have been reported on the possible association between TP53 C215G polymorphisms and CRC susceptibility. The G/G variant genotype was found to be associated with an increased risk of CRC in
Japanese, Korean and Indian Kashmiri populations (36-38). A case-control study involving 444 sporadic CRC patients in China also reported that the $\mathrm{G} / \mathrm{G}$ variant genotype was associated with an increased risk of CRC (39). In addition, an earlier study conducted by our group (40) revealed that the G/G genotype had a significant risk association with sporadic CRC susceptibility in a Malaysian population (OR, 2.047; CI, 1.063-4.044; $\mathrm{P}=0.013$ ). By contrast, meta-analyses conducted by Economopoulos et al (41) and Dahabreh et al (42) did not identify any significant risk association between G/G genotype and CRC susceptibility. Furthermore, Oh et al (43) reported that the variant genotype of TP53 $\mathrm{C} 215 \mathrm{G}$ was associated with a decreased risk of CRC.

Notably, in addition to their association with sporadic CRC, the variant genotypes of both SNPs investigated in the present study (A/A in CCNDI and G/G in TP53), exhibited a significant association with the risk of familial CRC (Table IV). However, few other studies have been conducted on the association of these SNPs with familial CRC susceptibility risk, and the results have been contradictory. In a study by Chen et al (44), CCND1 G870A was demonstrated to contribute to the early onset of CRC in cases of Lynch syndrome, whilst the TP53 C215G SNP was not. In a meta-analysis involving 20 different populations, the variant allele of $C C N D 1$ G870A was found to be significantly associated with an elevated CRC risk (OR, 1.23); however, no association with CRC risk was observed in Lynch syndrome patients (32). Rather than focusing on CRC susceptibility risk, the majority of previous studies have been focusing on the impact of CCNDI G870A and TP53 C215G on the age of onset in familial CRC cases, including cases of Lynch syndrome $(45,46)$. Krüger et al $(47)$ observed no association between $C C N D 1$ G870A and age of onset of Lynch syndrome among 406 MMR mutation carriers. Conflicting results also have been reported regarding the association of TP53 C215G polymorphism with the risk of CRC in Lynch syndrome patients. In other studies, the age of diagnosis of CRC in Lynch syndrome patients was not associated with TP53 C215G genotype $(46,48)$. In the present study, CRC patients identified to harbor MMR mutations were excluded, and the association of the two SNPs with age of onset of CRC in Lynch syndrome patients was therefore not investigated.

In summary, our results provide evidence of the effect of CCND1 G870A and TP53 C215G polymorphisms on CRC susceptibility risk. Despite the small sample size, the two SNPs have been observed to contribute to the susceptibility risk of sporadic and familial CRC in a Malaysian population. Individuals with $C C N D 1$ G870A A/A and TP53 C215G G/G genotypes in particular may have a higher risk for sporadic and familial CRC susceptibility. However, further studies into polymorphisms of other genes involved in pathways associated with sporadic and familial CRC in larger sample size, in addition to functional studies, are required to confirm these findings.

\section{Acknowledgements}

The authors would like to thank Dato' Dr Muhammad Radzi Abu Hassan (Hospital Sultanah Bahiyah) and Dr Ahmad Shanwani Mohd Sidek (Hospital Raja Perempuan Zainab II) 
for their assistance in recruiting the study subjects. The authors also wish to thank all the study participants for their contribution. This study was supported by a USM Research University grant (no. 1001/PPSP/812070).

\section{References}

1. Ferlay J, Soerjomataram I, Ervik M, Dikshit R, Eser S, Mathers C, Rebelo M, Parkin DM, Forman D and Bray F. GLOBOCAN 2012 v1.0. Cancer Incidence and Mortality Worldwide: IARC CancerBase No. 11 (Internet). International Agency for Research on Cancer, Lyon, France, 2013. Available from http://globocan. iarc.fr. Accessed July 27, 2015

2. Goh KL, Quek KF, Yeo GT, Hilmi IN, Lee CK, Hasnida N, Aznan M, Kwan KL and Ong KT: Colorectal cancer in Asians: A demographic and anatomic survey in Malaysian patients undergoing colonoscopy. Aliment Pharmacol Ther 22: 859-864, 2005.

3. National Cancer Registry: Malaysia Cancer Statistics - Data and Figure: Peninsular Malaysia 2006. National Cancer Registry, Ministry of Health Malaysia, Kuala Lumpur, 2006.

4. Zahary MN, Kaur G, Hassan MR, Sidek AS, Singh H, Yeh LY and Ankathil R: Germline mutation and protein expression analysis of mismatch repair genes MSH6 and PMS2 in Malaysian Lynch syndrome patients. Int J Colorectal Dis 29: 261-262, 2014.

5. Sherr CJ: Cancer cell cycles. Science 274: 1672-1677, 1996.

6. Donnellan R and Chetty R: Cyclin D1 and human neoplasia. Mol Pathol 51: 1-7, 1998

7. Zheng Y, Shen H, Sturgis EM, Wang LE, Eicher SA, Strom SS, Frazier ML, Spitz MR and Wei Q: Cyclin D1 polymorphism and risk for squamous cell carcinoma of the head and neck: A case-control study. Carcinogenesis 22: 1195-1199, 2001

8. Porter TR, Richards FM, Houlston RS, Evans DG, Jankowski JA, Macdonald F, Norbury G, Payne SJ, Fisher SA, Tomlinson I and Maher ER: Contribution of cyclin d1 (CCND1) and E-cadherin (CDH1) polymorphisms to familial and sporadic colorectal cancer. Oncogene 21: 1928-1933, 2002.

9. Wang L, Habuchi T, Takahashi T, Mitsumori K, Kamoto T, Kakehi Y, Kakinuma H, Sato K, Nakamura A, Ogawa O and Kato T: Cyclin D1 gene polymorphism is associated with an increased risk of urinary bladder cancer. Carcinogenesis 23 : 257-264, 2002

10. Wang L, Habuchi T, Mitsumori K, Li Z, Kamoto T, Kinoshita H, Tsuchiya N, Sato K, Ohyama C, Nakamura A, et al: Increased risk of prostate cancer associated with AA genotype of cyclin D1 gene A870G polymorphism. Int J Cancer 103: 116-120, 2003

11. Lane DP: Cancer. p53, guardian of the genome. Nature 358: 15-16, 1992.

12. Levine AJ: p53, the cellular gatekeeper for growth and division. Cell 88: 323-331, 1997.

13. Sullivan A, Syed N, Gasco M, Bergamaschi D, Trigiante G, Attard M, Hiller L, Farrell PJ, Smith P, Lu X and Crook T: Polymorphism in wild-type p53 modulates response to chemotherapy in vitro and in vivo. Oncogene 23: 3328-3337, 2004.

14. Hong Y, Eu KW, Seow-Choen F, Fook-Chong S and Cheah PY: GG genotype of cyclin D1 G870A polymorphism is associated with increased risk and advanced colorectal cancer in patients in Singapore. Eur J Cancer 41: 1037-1044, 2005.

15. Cao Z, Song JH, Park YK, Maeng EJ, Nam SW, Lee JY and Park WS: The p53 codon 72 polymorphism and susceptibility to colorectal cancer in Korean patients. Neoplasma 56 114-118, 2009.

16. Umar A, Boland CR, Terdiman JP, Syngal S, de la Chapelle A, Rüschoff J, Fishel R, Lindor NM, Burgart LJ, Hamelin R, et al: Revised Bethesda Guidelines for hereditary nonpolyposis colorectal cancer (Lynch syndrome) and microsatellite instability. J Natl Cancer Inst 96: 261-268, 2004.

17. Tárraga López PJ, Albero JS and Rodríguez-Montes JA: Primary and secondary prevention of colorectal cancer. Clin Med Insights Gastroenterol 7: 33-46, 2014.

18. Marin JJ, Sanchez de Medina F, Castaño B, Bujanda L, Romero MR, Martinez-Augustin O, Moral-Avila RD and Briz O: Chemoprevention, chemotherapy and chemoresistance in colorectal cancer. Drug Metab Rev 44: 148-172, 2012.

19. Sengupta N, Gill KA, MacFie TS, Lai CS, Suraweera N, Mcdonald S and Silver A: Management of colorectal cancer: A role for genetics in prevention and treatment? Pathol Res Pract 204: 469-477, 2008.
20. Gryfe R, Swallow C, Bapat B, Redston M, Gallinger S and Couture J: Molecular biology of colorectal cancer. Curr Probl Cancer 21: 233-300, 1997.

21. Bellacosa A: Genetic hits and mutation rate in colorectal tumorigenesis: Versatility of Knudson's theory and implications for cancer prevention. Genes Chromosomes Cancer 38: 382-388, 2003.

22. Shtutman M, Zhurinsky J, Simcha I, Albanese C, D'Amico M, Pestell $\mathrm{R}$ and Ben-Ze'ev A: The cyclin D1 gene is a target of the beta-catenin/LEF-1 pathway. Proc Natl Acad Sci U S A 96: 5522-5527, 1999.

23. Betticher DC, Thatcher N, Altermatt HJ, Hoban P, Ryder WD and Heighway J: Alternate splicing produces a novel cyclin D1 transcript. Oncogene 11: 1005-1011, 1995.

24. Solomon DA, Wang Y, Fox SR, Lambeck TC, Giesting S, Lan Z, Senderowicz AM, Conti CJ and Knudsen ES: Cyclin D1 splice variants. Differential effects on localization, RB phosphorylation and cellular transformation. J Biol Chem 278: 30339-30347, 2003.

25. Sawa H, Ohshima TA, Ukita H, Murakami H, Chiba Y, Kamada H, Hara M and Saito I: Alternatively spliced forms of cyclin D1 modulate entry into the cell cycle in an inverse manner. Oncogene 16: 1701-1712, 1998.

26. Fearon ER and Vogelstein B: A genetic model for colorectal tumorigenesis. Cell 61: 759-767, 1990.

27. Whibley C, Pharoah PD and Hollstein M: p53 polymorphisms: Cancer implications. Nat Rev Cancer 9: 95-107, 2009.

28. Thomas M, Kalita A, Labrecque S, Pim D, Banks L and Matlashewski G: Two polymorphic variants of wild-type p53 differ biochemically and biologically. Mol Cell Biol 19: 1092-1100, 1999.

29. Bergamaschi D, Gasco M, Hiller L, Sullivan A, Syed N Trigiante G, Yulug I, Merlano M, Numico G, Comino A, et al: p53 polymorphism influences response in cancer chemotherapy via modulation of p73-dependent apoptosis. Cancer Cell 3: 387-402, 2003.

30. Pim D and Banks L: $\mathrm{p} 53$ polymorphic variants at codon 72 exert different effects on cell cycle progression. Int J Cancer 108: 196-199, 2004.

31. Marin MC, Jost CA, Brooks LA, Irwin MS, O'Nions J, Tidy JA, James N, McGregor JM, Harwood CA, Yulug IG, et al: A common polymorphism acts as an intragenic modifier of mutant p53 behaviour. Nat Genet 25: 47-54, 2000.

32. Zhang LQ, Wang J, Shang JQ, Bai JL, Liu FY, Guan X and Zhou JN: Cyclin D1 G870A polymorphism and colorectal cancer susceptibility: A meta-analysis of 20 populations. Int $\mathrm{J}$ Colorectal Dis 26: 1249-1255, 2011.

33. Yang Y, Wang F, Shi C, Zou Y, Qin H and Ma Y: Cyclin D1 G870A polymorphism contributes to colorectal cancer susceptibility: Evidence from a sytematic review of 22 case-control studies. PLoS One 7: e36813, 2012.

34. Sameer AS, Parray FQ, Dar MA, Nissar S, Banday MZ, Rasool S, Gulzar GM, Chowdri NA and Siddiqi MA: Cyclin D1 G870A polymorphism and risk of colorectal cancer: A case control study. Mol Med Rep 7: 811-815, 2013.

35. Jiang J, Wang J, Suzuki S, Gajalakshmi V, Kuriki K, Zhao Y, Nakamura S, Akasaka S, Ishikawa $\mathrm{H}$ and Tokudome S: Elevated risk of colorectal cancer associated with the AA genotype of the cyclin D1 A870G polymorphism in an Indian population. J Cancer Res Clin Oncol 132: 193-199, 2006.

36. Sameer AS, Shah ZA, Syeed N, Banday MZ, Bashir SM, Bhat BA and Siddiqi MA: TP53 Pro47Ser and Arg72Pro polymorphisms and colorectal cancer predisposition in an ethnic Kashmiri population. Genet Mol Res 9: 651-660, 2010.

37. Joshi AM, Budhathoki S, Ohnaka K, Mibu R, Tanaka M, Kakeji Y, Maehara Y, Okamura T, Ikejiri K, Futami K, et al: TP53 R72P and MDM2 SNP309 polymorphisms and colorectal cancer risk: The Fukuoka Colorectal Cancer Study. Jpn J Clin Oncol 41: 232-238, 2011.

38. Song HR, Kweon SS, Kim HN, Piao JM, Yun WJ, Choi JS, Hwang JE, Yoon JY, Kim HR, Park YK, et al: p53 codon 72 polymorphism in patients with gastric and colorectal cancer in a Korean population. Gastric Cancer 14: 242-248, 2011.

39. Zhang Y, Liu L, Tang Y, et al: Polymorphisms in TP53 and MDM2 contribute to higher risk of colorectal cancer in Chinese population: A hospital-based, case control study. Mol Biol Rep 39: 9661-9668, 2012.

40. Aizat AA, Shahpudin SN, Mustapha MA, et al: Association of Arg72Pro of P53 polymorphism with colorectal cancer susceptibility risk in Malaysian population. Asian Paci J Cancer Prev 12: 2909-2913, 2011. 
41. Economopoulos KP, Sergentanis TN, Zagouri F and Zografos GC: Association between p53 Arg72Pro polymorphism and colorectal cancer risk: A meta-analysis. Onkologie 33: 666-674, 2010.

42. Dahabreh IJ, Linardou H, Bouzika P, Varvarigou V and Murray S: TP53 Arg72Pro polymorphism and colorectal cancer risk: A systematic review and meta-analysis. Cancer Epidemiol Biomarkers Prev 19: 1840-1847, 2010

43. Oh J, Kim JW, Lee BE, Jang MJ, Chong SY, Park PW, Hwang SG, Oh D and Kim NK: Polymorphisms of the pri-miR-34b/c promoter and TP53 codon 72 are associated with risk of colorectal cancer. Oncol Rep 31: 995-1002, 2014.

44. Chen J, Etzel CJ, Amos CI, Zhang Q, Viscofsky N, Lindor NM, Lynch PM and Frazier ML: Genetic variant in the cell cycle control pathways contribute to early onset colorectal cancer in Lynch syndrome. Cancer Causes Control 20: 1769-1777, 2009.

45. Krüger S, Bier A, Engel C, Mangold E, Pagenstecher C, von Knebel Doeberitz M, Holinski-Feder E, Moeslein G, Schulmann K, Plaschke J, et al: The p53 codon 72 variation is associated with the age of onset of hereditary non-polyposis colorectal cancer (HNPCC). J Med Genet 42: 769-773, 2005.
46. Sotamaa K, Liyanarachchi S, Mecklin JP, Järvinen H, Aaltonen LA, Peltomäki P and de la Chapelle A: p53 codon 72 and MDM2 SNP309 polymorphisms and age of colorectal cancer onset in Lynch syndrome. Clin Cancer Res 11: 6840-6844, 2005.

47. Krüger S, Engel C, Bier A, Mangold E, Pagenstecher C, Doeberitz Mv, Holinski-Feder E, Moeslein G, Keller G, Kunstmann E, et al: Absence of association between cyclin D1 (CCND1) G870A polymorphism and age of onset in hereditary nonpolyposis colorectal cancer. Cancer Lett 236: 191-197, 2006.

48. Talseth BA, Meldrum C, Suchy J, Kurzawski G, Lubinski J and Scott RJ: MDM2 SNP309 T>G alone or in combination with the TP53 R72P polymorphism does not appear to influence disease expression and age of diagnosis of colorectal cancer in HNPCC patients. Int J Cancer 120: 563-565, 2007. 